\title{
Influence of Reoperations on Long-Term Quality of Life After Restrictive Procedures: A Prospective Study
}

\author{
Ruben Schouten • Dorothee C. M. S. Wiryasaputra • \\ Francois M. H. van Dielen • Wim G. van Gemert • \\ Jan Willem M. Greve
}

Published online: 11 January 2011

(C) The Author(s) 2011. This article is published with open access at Springerlink.com

\begin{abstract}
Quality of life improves after bariatric surgery. However, long-term results and the influence of reoperations are not well known. A prospective quality of life assessment before, 1 and 7 years after laparoscopic adjustable gastric banding (LAGB) and vertical banded gastroplasty (VBG) was performed in order to determine the influence of reoperations during follow-up. One hundred patients were included in the study. Fifty patients underwent VBG and 50 LAGB. Patients completed the quality of life questionnaires prior to surgery and two times during follow-up. Health-related quality of life (HRQoL) questionnaires included the Nottingham Health Profile I and II and the Sickness Impact Profile 68. Follow-up was $84 \%$ with a mean duration of 84 months (7 years). During follow-up, $65 \%$ of VBG patients underwent conversion to Roux-en-Y gastric bypass while $44 \%$ of LAGB patients underwent a reoperation or conversion. One year after the procedure, nearly all quality-of-life parameters significantly improved. After 7 years, the Nottingham Health Profile (NHP)-I domain "physical ability", the NHP-II and the SIP68 domains "mobility control", "social behavior", and "mobility range" were still significantly improved in both groups. The domains "emotional reaction", "social isola-
\end{abstract}

R. Schouten $(\bowtie) \cdot$ W. G. van Gemert · J. W. M. Greve Department of Surgery, Atrium Medical Centre Parkstad, P.O. Box 4446, 6401 CX Heerlen, The Netherlands e-mail: schoutenruben@hotmail.com

D. C. M. S. Wiryasaputra

Department of Surgery, Maastricht University Medical Centre, Maastricht, The Netherlands

F. M. H. van Dielen

Department of Surgery, Maxima Medical Centre,

Veldhoven, The Netherlands tion" (NHP-I), and "emotional stability" (SIP-68) remained significantly improved in the VBG group while this was true for the domain "energy level" (NHP-I) in the LAGB group. Both the type of procedure and reoperations during follow-up were not of significant influence on the HRQoL results. Weight loss and decrease in comorbidities were the only significant factors influencing quality of life. Restrictive bariatric surgery improves quality of life. Although results are most impressive 1 year after surgery, the improvement remains significant after long-term followup. Postoperative quality of life is mainly dependent on weight loss and decrease in comorbidities and not on the type of procedure or surgical complications.

Keywords Health-related quality of life - Restrictive procedures $\cdot$ LAGB $\cdot$ VBG $\cdot$ Long-term results

\section{Introduction}

Over the past three decades, quality of life has become an increasingly important aspect of clinical investigation and patient care. The World Health Organization defines quality of life as "a state of complete physical, mental, and social well-being and not merely the absence of disease or infirmity". For most patients, quality of life is more important than the traditional outcome measures in medical care [1]. Morbid obesity is a lifelong, progressive disease of fat storage manifested by medical, physical, psychological, social, and economic comorbidities and increases the risk of developing life-threatening diseases [2]. The presentation of these problems in obese persons is related to the amount of excess weight [3-5]. It is important to state that morbid obesity interferes unfavorably with general well-being and the psyche of the patient. Results of quality-of-life assess- 
ments of morbidly obese patients show that quality of life is better after surgically induced weight loss and seems not to be related to the type of surgical procedure or to surgical complications [6, 7]. The positive effects of bariatric surgery on the quality of life after long-term follow-up indicate that the quality of life is significantly improved in the short term while it diminishes in the long term. However, quality of life remains better compared to preoperative values [8-18]. After long-term follow-up, the type of procedure seems to be less important than the overall weight loss and decrease in comorbidities $[8,9]$. It is however known that a substantial number of reoperations are necessary during follow-up after restrictive bariatric procedures. The influence of reoperations on long-term quality-of-life results is not well known. Literature on this subject is limited and suggests it might be an unimportant factor $[10,11]$. In our institution, a randomized prospective study comparing laparoscopic adjustable gastric banding (LAGB) with open vertical banded gastroplasty (VBG) was initiated in 1998 and 2-year clinical results are published elsewhere [12]. However, the latter study also included preand postoperative quality-of-life assessment. The present study aims to describe long-term quality-of-life results and to determine if reoperations during follow-up are of influence on the results.

\section{Patients and Methods}

\section{Patients and Study Design}

One hundred morbidly obese patients with a body mass index (BMI) above $40 \mathrm{~kg} / \mathrm{m}^{2}$ or above $35 \mathrm{~kg} / \mathrm{m}^{2}$ with obesity-related comorbidities were selected to undergo either LAGB or open VBG. All patients were aged between 18 and 60 years and had not succeeded in losing weight through several dietary programs. Patients with severe psychiatric disorders interfering with postoperative followup and compliance or who had prior bariatric and/or gastric surgery were excluded from the study. After obtaining written informed consent, patients were randomly assigned to the different operations by a computer-generated randomization list. The initial study and long-term follow-up study were approved by the medical ethical committee of the Maastricht University Medical Centre, the Netherlands. Before admission for surgery, all patients were asked to complete quality of life questionnaires. After discharge, all patients were evaluated in the outpatient clinic after 1 and 6 weeks and 3, 6, 12, and 24 months. After this period, patients were evaluated at least once a year. However, patients were asked to complete quality-of-life questionnaire only preoperatively, after 6 weeks and 12 months. In 2007 , all patients were more than 5 years past their initial surgery and were approached to complete the same qualityof-life questionnaires. Since baseline, visit four patients had died. Therefore, 96 of the initial 100 patients were asked to participate.

\section{Quality of Life Analysis}

Patients' health-related quality of life (HRQoL) was investigated by using three validated methods. The Nottingham Health Profile part I (NHP-I) and part II (NHP-II) were used to provide an indication of the patient's perceived emotional, social, and physical health problems [13]. In part I, 38 questions are distributed over six sub-areas with each question assigned a weighted value; the sum of all weighted values in a given sub-area adds up to a score between 0 (best score) and 100 (worst score). The six specific domains of life are: mobility, pain, energy, sleep, social isolation, and emotional reaction. In part II, the questionnaire relates to those areas of task performance most affected by health. It concerns seven statements that refer to the effects of health problems on occupation, ability to perform domestic tasks, hobbies, personal relationships, sex life, social life, and holidays. The NHP-II is given as a single score ranging between 7 (best score) and 21 (worst score). Finally, the Sickness Impact Profile 68 (SIP-68) is known to be a valid and reliable instrument [14-16]. It is intended for measuring the outcomes of care in health surveys, program planning, in policy formation, and in monitoring patients' progress. The SIP-68 includes 68 items and every item contains a statement on behavior. The items are divided in six categories: somatic autonomy ("the level to which an individual is autonomous in his or her basic somatic functioning"; 17 items), mobility control ("the level to which an individual has control over his body"; 12 items), psychological autonomy and communication ("the level to which an individual is able to function without help of others in areas of mental functioning"; 11 items), social behavior ("possible consequences of a health deviation on a person's functioning in relation to other persons"; 12 items), emotional stability ("assessment of the effect of the health status on the emotional status of a person"; six items), and mobility range ("the influence of a health status on usual tasks and on the range of actions to which a person has (limited) disposition"; 10 items). In every category, the score is calculated in the same manner: 0 is the lowest and best possible score while the number of items (respectively $17,12,11,12,6$, and 10) is identical to the highest and worst score [14]. The relation between preoperative and postoperative HRQoL 1 and 7 years after LAGB and VBG was investigated using these questionnaires. Furthermore, a subgroup analysis was performed in both groups in order to investigate if reoperations and conversions after restrictive procedures had any influence on HRQoL. 
Statistical Analysis

Statistical analysis using the SPSS 15.0.0 statistical package (SPSS Inc., Chicago, IL, USA) was performed nonparametrically and two-sided. The Student's $t$ test was used to calculate differences between the groups. In case of a skewed distribution the Mann-Whitney $U$ test was used for comparison between the groups and the Wilcoxon signedrank test for comparison in one group throughout time. To determine if certain factors were of significant influence on HRQoL results, Pearson's correlation coefficient was used and Kendall's tau in case of ranked data distribution. Data are given as mean and standard deviation. A $p$ value of $p<$ 0.05 or $p<0.01$ (where applicable) was denoted as statistically significant.

\section{Results}

\section{Group Characteristics}

Four patients died during the follow-up period; two patients as a result of postoperative complications (both VBG), one due to ovarian cancer (4 years after LAGB), and one as a result of a gynecological infection (5 years after VBG). Data on postoperative complications, reoperations, and weight loss from the last two patients are included in the analysis up until their last visit to the outpatient clinic. Seven patients could not be traced and were lost to follow-up and five patients were not willing to fill out the questionnaires or did not manage to return them completely despite repeated attempts to contact these patients. The long-term HRQoL study eventually included 84 patients with a mean follow-up period of 84 months (7 years). The study population consisted of 68 women and 16 men. From this group, 40 patients initially underwent VBG and 44 patients LAGB. Patients in the VBG and LAGB group were comparable regarding age, preoperative weight and BMI (Table 1).

\section{Weight Loss}

Long-term weight loss was significant in VBG patients (BMI decrease from 46 to $32 \mathrm{~kg} / \mathrm{m}^{2}$ ) and LAGB patients
(BMI decrease from 47 to $35 \mathrm{~kg} / \mathrm{m}^{2}$ ). However, weight loss after 7 years was significantly higher after VBG than after LAGB with a BMI of 32 versus $35 \mathrm{~kg} / \mathrm{m}^{2}(p<0.01)$ and an EWL (amount of kilograms lost since baseline $\times 100$ /excess weight) of $69 \%$ versus $54 \%(p<0.05)$.

\section{Reoperations}

After 7 years, 14 patients (35\%) still had VBG while 26 patients (65\%) were converted to Roux-en-Y gastric bypass (RYGB) because of staple line dehiscence (22 patients) or recurrent outlet stenosis (four patients; Table 2). However, this had no effect on the long-term weight loss results (EWL of $69 \%$ and $68 \%$, respectively). In the LAGB group, 25 patients $(57 \%)$ did not have a reoperation. Fourteen patients $(32 \%)$ underwent a refixation or replacement of the band (14 patients) because of band slippage. Conversion to RYGB and biliopancreatic diversion was necessary in three and two patients $(11 \%)$, respectively, because of severe pouch dilatation and band erosion. Comparing the weight loss results of LAGB patients and reoperated (nonconverted) LAGB patients also did not show a significant difference (EWL 54\% and 57\%, respectively).

\section{Comorbidities}

In Table 3, the total number of obesity-related comorbidities in the VBG group and the LAGB group are summarized. There are no significant differences between the groups preoperatively $(p=0.97)$. Comparing pre- and postoperative comorbidities after 1 and 7 years show that the comorbidities significantly decreased after surgery (both $p<0.01$ ). Furthermore, the decrease is stable during follow-up; the results are comparable after 1 and 7 years without differences between the groups.

\section{Quality of Life Assessment After 1 Year}

Table 4 shows the preoperative and postoperative HRQoL results 1 year after surgery for VBG and LAGB patients. All domains in the NHP-I and NHP-II significantly improved postoperatively in both groups except "social isolation" in the LAGB group $(p=0.10)$. The six categories
Table 1 Group characteristics and final weight loss

\begin{tabular}{lccr}
\hline & VBG $(n=40)$ & LAGB $(n=44)$ & $p$ Value $^{\mathrm{a}}$ \\
\hline Male/female & $6: 34$ & $10: 34$ & - \\
Age (years) & $37 \pm 10$ & $39 \pm 9$ & 0.32 \\
Preoperative weight $(\mathrm{kg})$ & $131 \pm 24$ & $133 \pm 21$ & 0.87 \\
Preoperative BMI $\left(\mathrm{kg} / \mathrm{m}^{2}\right)$ & $46 \pm 6$ & $47 \pm 6$ & 0.82 \\
Final BMI $\left(\mathrm{kg} / \mathrm{m}^{2}\right)$ & $32 \pm 5$ & $35 \pm 7$ & $<0.01$ \\
Final EWL $(\%)$ & $69 \pm 23$ & $54 \pm 25$ & $<0.05$ \\
\hline
\end{tabular}


Table 2 Number of patients with or without reoperation/conversion during follow-up

\begin{tabular}{llr}
\hline & VBG $(n=40)$ & LAGB $(n=44)$ \\
\hline No reoperation & $14(35 \%)$ & $25(57 \%)$ \\
Reoperation & - & $14(32 \%)$ \\
Conversion & $26(65 \%)$ & $5(11 \%)$ \\
\hline
\end{tabular}

of the SIP-68 all showed significant improvement except "psychic autonomy and communication" in both groups $(p=0.21$ in the VBG group and $p=0.14$ in the LAGB group). Also, the category "somatic autonomy" did not significantly improve in the VBG group $(p=0.06)$. Overall, it can be stated that HRQoL significantly improved 1 year after surgery with minor differences between VBG and LAGB.

\section{Quality of Life Assessment After 7 Years}

The NHP-I showed improvement in all domains 7 years after surgery (Table 5) but in the VBG group this reached statistical significance in only three of the six domains ("emotional reaction" $(p<0.01)$, "social isolation" $(p<0.01)$ and "physical abilities" $(p<0.01))$. In the LAGB group, only two of the six domains were significantly improved ("energy level" ( $p<$ $0.05)$ and "physical ability" $(p<0.01))$. The NHP-II improved significantly in both groups $(p<0.01)$. The categories of the SIP-68 all improved except for "psychic autonomy and communication". In the VBG group, there was a significant improvement of four of the six categories ("mobility control" $(p<0.01)$, "social behavior" $(p<0.05)$, "emotional stability" $(p<0.05)$ and "mobility range" $(p<0.05))$. In the LAGB group, the same significant improvements were noted except for "emotional stability" ( $p=0.78)$. Overall, HRQoL was still improved 7 years after surgery. Differences between VBG and LAGB are minimal; in both groups, about half of the values were significantly improved.

\section{Quality of Life Assessment: VBG Versus Conversion} to RYGB

As mentioned before, 26 patients in the VBG group were converted to RYGB and 19 patients underwent a reopera- tion or conversion after LAGB because of complications (Table 2). Although this had no effect on the long-term weight loss results, it was hypothesized it could have an effect on the HRQoL of patients. Therefore, a subgroup analysis was performed comparing patients in the VBG and LAGB group with or without reoperation or conversion. Table 6 represents the HRQoL results 7 years postoperatively subdivided into patients with or without conversion to RYGB. Again, all values improved in both groups except the SIP-68 categories "somatic autonomy" and "psychic autonomy and communication". Because of smaller patient numbers in both groups, a lower number of values reached statistical significance. More importantly, there were no differences between the nonconverted and converted patient group. Both had a significant improvement in "social isolation", "physical abilities" (both NHPI), the NHP-II and "mobility control" (SIP-68).

\section{Quality of Life Assessment: LAGB With or Without Reoperation}

In the LAGB group without a reoperation during follow-up, most values were improved after 7 years although two values worsened ("sleep" and "psychic autonomy and communication", $p$ values of 0.73 and 0.21 , respectively). Because of smaller patient numbers, only three values reached statistical significance; "physical abilities" $(p<$ $0.01)$, NHP-II $(p<0.01)$, and "mobility range" $(p<0.05)$. In patients having a reoperation after LAGB during followup, these numbers were slightly different. The reoperated patient group had more improved values that reached statistical significance (five compared to three values; "physical abilities" $(p<0.01)$, NHP-II $(p<0.01)$, "somatic autonomy" $(p<0.05)$, "mobility control" $(p<0.05)$, and "social behavior" $(p<0.05))$. Overall, HRQoL results are not negatively influenced by reoperations after LAGB and appear to be even better (Table 7).

Quality of Life Assessment: What Factors Are of Influence?

To determine if certain factors were of significant influence on the HRQoL results, Pearson's and Kendall's tau

Table 3 Obesity-related comorbidities pre- and postoperatively

\begin{tabular}{lllr}
\hline & VBG $(n)$ & LAGB $(n)$ & $p$ Value \\
\hline Total comorbidities (preoperatively) & $1.3 \pm 1.1(50)$ & $1.3 \pm 1.0(50)$ & $0.97^{\mathrm{a}}$ \\
Total comorbidities (1 year postoperatively) & $0.5 \pm 0.9(45)$ & $0.5 \pm 0.8(44)$ & $<0.01^{\mathrm{b}}$ \\
Toetal comorbidities (7 year postoperatively) & $0.6 \pm 0.9(40)$ & $0.6 \pm 0.8(44)$ & $<0.01^{\mathrm{b}}$ \\
\hline
\end{tabular}

${ }^{a}$ Total comorbidities of the VBG group compared to the LAGB group (Mann-Whitney test)

${ }^{\mathrm{b}}$ Total comorbidities pre- and postoperatively compared within a group (Wilcoxon signed-rank test) 
Table 4 Preoperative and postoperative HRQoL results 1 year after surgery

\begin{tabular}{|c|c|c|c|c|c|c|}
\hline & $\begin{array}{l}\text { VBG } \\
\text { (preoperative; } \\
n=50 \text { ) }\end{array}$ & $\begin{array}{l}\text { VBG } \\
(1 \text { year postoperative; } \\
n=45)\end{array}$ & $p$ Value $^{\mathrm{a}}$ & $\begin{array}{l}\text { LAGB } \\
\text { (preoperative; } \\
n=50 \text { ) }\end{array}$ & $\begin{array}{l}\text { LAGB } \\
(1 \text { year postoperative; } \\
n=45)\end{array}$ & $p$ Value $^{\mathrm{a}}$ \\
\hline \multicolumn{7}{|l|}{ NHP-I } \\
\hline Energy level & 46.3 & 13.7 & $<0.01$ & 42.8 & 11.6 & $<0.01$ \\
\hline Pain & 25.8 & 8.8 & $<0.01$ & 19.5 & 9.8 & $<0.01$ \\
\hline Emotional reaction & 21.4 & 10.4 & $<0.01$ & 15.0 & 5.0 & $<0.01$ \\
\hline Sleep & 24.7 & 10.1 & $<0.01$ & 16.1 & 6.6 & $<0.05$ \\
\hline Social isolation & 21.0 & 6.8 & $<0.01$ & 16.4 & 5.8 & 0.10 \\
\hline Physical abilities & 30.3 & 6.7 & $<0.01$ & 25.0 & 9.4 & $<0.01$ \\
\hline NHP-II & 12.7 & 7.5 & $<0.01$ & 13.0 & 7.7 & $<0.01$ \\
\hline \multicolumn{7}{|l|}{ SIP-68 } \\
\hline Somatic autonomy & 2.7 & 0.8 & 0.06 & 3.6 & 1.4 & $<0.01$ \\
\hline Mobility control & 29.3 & 7.5 & $<0.01$ & 22.3 & 7.8 & $<0.01$ \\
\hline $\begin{array}{l}\text { Psychic autonomy and } \\
\text { communication }\end{array}$ & 11.1 & 7.0 & 0.21 & 8.3 & 4.6 & 0.14 \\
\hline Social behavior & 29.8 & 12.0 & $<0.01$ & 26.7 & 9.9 & $<0.01$ \\
\hline Emotional stability & 22.0 & 12.9 & $<0.05$ & 15.5 & 5.4 & $<0.01$ \\
\hline Mobility range & 10.1 & 1.3 & $<0.01$ & 8.0 & 1.9 & $<0.01$ \\
\hline
\end{tabular}

${ }^{\mathrm{a}}$ Wilcoxon signed-rank test

correlations were calculated. Sex, age, and type of procedure (VBG or LAGB) had no significant correlation with any of the NHP-I domains, NHP-II or SIP-68 categories. Also, no correlations were found between HRQoL outcome after 7 years and reoperations or conversion during follow-up. The strongest correlation was found between HRQoL parameters and long-term weight loss. Eight out of the 13 domains were negatively correlated with weight loss after 7 years, i.e., more weight loss led to a better HRQoL score (NHP-I domains "energy level" $(P<0.01)$, "pain" $(p<0.01)$, "emotional reac-

Table 5 Preoperative and postoperative HRQoL results 7 year after surgery

\begin{tabular}{|c|c|c|c|c|c|c|}
\hline & $\begin{array}{l}\text { VBG } \\
\text { (preopearative; } \\
n=50 \text { ) }\end{array}$ & $\begin{array}{l}\text { VBG ( } 7 \text { years } \\
\text { postoperative; } \\
n=40 \text { ) }\end{array}$ & $p$ Value $^{\mathrm{a}}$ & $\begin{array}{l}\text { LAGB } \\
\text { (preoperative; } \\
n=50 \text { ) }\end{array}$ & $\begin{array}{l}\text { LAGB ( } 7 \text { years } \\
\text { postoperative; } \\
n=44 \text { ) }\end{array}$ & $p$ Value $^{\mathrm{a}}$ \\
\hline \multicolumn{7}{|l|}{ NHP-I } \\
\hline Energy level & 46.3 & 27.3 & 0.14 & 42.8 & 27.3 & $<0.05$ \\
\hline Pain & 25.8 & 15.8 & 0.25 & 19.5 & 14.1 & 0.06 \\
\hline Emotional reaction & 21.4 & 6.9 & $<0.01$ & 15.0 & 15.1 & 0.19 \\
\hline Sleep & 24.7 & 16.4 & 0.96 & 16.1 & 16.1 & 0.94 \\
\hline Social isolation & 21.0 & 4.4 & $<0.01$ & 16.4 & 12.8 & 0.21 \\
\hline Physical abilities & 30.3 & 9.7 & $<0.01$ & 25.0 & 9.9 & $<0.01$ \\
\hline NHP-II & 12.7 & 10.7 & $<0.01$ & 13.0 & 10.2 & $<0.01$ \\
\hline \multicolumn{7}{|l|}{ SIP-68 } \\
\hline Somatic autonomy & 2.7 & 2.6 & 0.50 & 3.6 & 2.1 & 0.25 \\
\hline Mobility control & 29.3 & 12.8 & $<0.01$ & 22.3 & 14.0 & $<0.05$ \\
\hline Psychic autonomy and communication & 11.1 & 14.1 & 0.25 & 8.3 & 12.0 & 0.12 \\
\hline Social behavior & 29.8 & 14.9 & $<0.05$ & 26.7 & 17.5 & $<0.01$ \\
\hline Emotional stability & 22.0 & 11.2 & $<0.05$ & 15.5 & 14.6 & 0.78 \\
\hline Mobility range & 10.1 & 2.8 & $<0.05$ & 8.0 & 3.4 & $<0.01$ \\
\hline
\end{tabular}

${ }^{\mathrm{a}}$ Wilcoxon signed-rank test 
Table 6 Preoperative and postoperative HRQoL results 7 year after surgery; nonconverted versus converted RYGB patients

\begin{tabular}{|c|c|c|c|c|c|}
\hline & $\begin{array}{l}\text { VBG } \\
\text { (preoperative; } n=50 \text { ) }\end{array}$ & $\begin{array}{l}\text { VBG } \\
\text { (nonconverted; } n=14 \text { ) }\end{array}$ & $p$ Value $^{\mathrm{a}}$ & $\begin{array}{l}\text { VBG } \\
\text { (converted to RYGB; } n=26 \text { ) }\end{array}$ & $p$ Value $^{\mathrm{a}}$ \\
\hline \multicolumn{6}{|l|}{ NHP-I } \\
\hline Energy level & 46.3 & 18.6 & 0.10 & 34.2 & 0.53 \\
\hline Pain & 25.8 & 18.0 & 0.94 & 14.2 & 0.10 \\
\hline Emotional reaction & 21.4 & 5.9 & 0.06 & 7.9 & 0.06 \\
\hline Sleep & 24.7 & 20.8 & 0.39 & 13.2 & 0.58 \\
\hline Social isolation & 21.0 & 4.1 & $<0.05$ & 4.7 & $<0.01$ \\
\hline Physical abilities & 30.3 & 6.2 & $<0.01$ & 12.1 & $<0.01$ \\
\hline NHP-II & 12.7 & 9.9 & $<0.01$ & 11.5 & $<0.01$ \\
\hline \multicolumn{6}{|l|}{ SIP-68 } \\
\hline Somatic autonomy & 2.7 & 2.2 & 0.86 & 3.2 & 0.28 \\
\hline Mobility control & 29.3 & 11.1 & $<0.05$ & 13.0 & $<0.05$ \\
\hline Psychic autonomy and communication & 11.1 & 6.4 & 0.74 & 19.2 & 0.20 \\
\hline Social behavior & 29.8 & 12.5 & 0.05 & 16.7 & 0.12 \\
\hline Emotional stability & 22.0 & 6.2 & 0.37 & 14.4 & 0.05 \\
\hline Mobility range & 10.1 & 1.2 & 0.07 & 4.9 & 0.12 \\
\hline
\end{tabular}

${ }^{\mathrm{a}}$ Wilcoxon signed-rank test

tion" $(p<0.05)$, "sleep" $(p<0.01)$, "social isolation" $(p<0.05)$, "physical abilities" $(p<0.01)$, and SIP-68 domains "mobility control" $(p<0.01)$ and "social behaviour" $(p<0.01))$. Furthermore, 11 of $13 \mathrm{HRQoL}$ domains were positively correlated with the total number of obesity related comorbidities, i.e., patients with more comorbidities had a higher score and thus lower quality of life. The NHP-I domains "energy level" ( $p<$
$0.01)$, "pain" $(p<0.01)$, "sleep" $(p<0.05)$, "social isolation" $(p<0.05)$ and "physical abilities" $(p<0.01)$, the NHP-II $(p<$ $0.01)$ and the SIP-68 domains "somatic autonomy" $(p<0.05)$, "mobility control" $(p<0.01)$, "psychic autonomy and communication" $(p<0.05)$, "social behavior" $(p<0.01)$, and "mobility control" $(p<0.01)$ were all significantly better in patients with fewer comorbidities.

Table 7 Preoperative and postoperative HRQoL results 7 year after surgery; LAGB patients without or with reoperation

\begin{tabular}{|c|c|c|c|c|c|}
\hline & $\begin{array}{l}\text { LAGB } \\
\text { (preoperative; } n=50 \text { ) }\end{array}$ & $\begin{array}{l}\text { LAGB } \\
\text { (no reoperation; } n=25 \text { ) }\end{array}$ & $p$ Value $^{\mathrm{a}}$ & $\begin{array}{l}\text { LAGB } \\
\text { (reoperation; } n=19 \text { ) }\end{array}$ & $p$ Value $^{\mathrm{a}}$ \\
\hline \multicolumn{6}{|l|}{ NHP-I } \\
\hline Energy level & 42.8 & 25.0 & 0.06 & 32.1 & 0.25 \\
\hline Pain & 19.5 & 14.2 & 0.47 & 14.0 & 0.02 \\
\hline Emotional reaction & 15.0 & 13.3 & 0.41 & 19.1 & 0.28 \\
\hline Sleep & 16.1 & 19.2 & 0.73 & 15.6 & 0.67 \\
\hline Social isolation & 16.4 & 10.8 & 0.59 & 17.1 & 0.21 \\
\hline Physical abilities & 25.0 & 9.2 & $<0.01$ & 11.5 & $<0.01$ \\
\hline NHP-II & 13.0 & 10.0 & $<0.01$ & 10.6 & $<0.01$ \\
\hline \multicolumn{6}{|l|}{ SIP-68 } \\
\hline Somatic autonomy & 3.6 & 2.2 & 0.08 & 2.0 & $<0.05$ \\
\hline Mobility control & 22.3 & 14.4 & 0.17 & 13.1 & $<0.05$ \\
\hline Psychic autonomy and communication & 8.3 & 10.9 & 0.21 & 14.3 & 0.31 \\
\hline Social behavior & 26.7 & 18.2 & 0.10 & 15.6 & $<0.05$ \\
\hline Emotional stability & 15.5 & 13.6 & 0.70 & 21.7 & 0.64 \\
\hline Mobility range & 8.0 & 2.0 & $<0.05$ & 6.5 & 0.14 \\
\hline
\end{tabular}

${ }^{\text {a }}$ Wilcoxon signed-rank test 


\section{Discussion}

Morbidly obese patients have an impaired quality of life indicated by significantly worse values on nearly all quality-of-life tests compared to control groups from a normal weight population [17]. Literature shows that surgically induced weight loss results in a better HRQoL in the short- and midterm postoperative period [18-22]. After long-term follow-up HRQoL decreases but remains significantly better compared to preoperative values [8-10, 18-20, 23-27]. Although some studies report that variables like gender, marital status, and sport activities are significant factors in HRQoL results [28, 29] most studies agree that improvement and deterioration of HRQoL are mainly associated with the magnitude of weight loss and weight regain, respectively $[8,9,18-20,23,24,26,27,30,31]$. This is confirmed in the present study; significant correlations between weight loss and improvement of eight of the 13 HRQoL domains were found. The total number of obesity-related comorbidities also had a significant correlation with 11 HRQoL domains, i.e., less comorbidities led to a better quality of life.

Another important phenomenon in HRQoL analysis after bariatric surgery is the peak improvement after the first postoperative year and stabilization afterwards. This phenomenon has been shown in previous studies [6, 9, 26, 29, $32,33]$. The present study shows the same trend; 1 year after surgery, practically all values in the HRQoL analysis were significantly improved while after 7 years this was reduced to about half of the values. Therefore, although the quality of life is at its best 1-2 years after surgery, it remains improved after long-term follow-up compared to the preoperative quality of life. An illustration of this is provided in Fig. 1. However, a major issue in comparing studies focusing on HRQoL after bariatric surgery is that a variety of questionnaires are used. This makes true comparison nearly impossible. On the other hand, all studies report improvement in HRQoL after short, midand long-term follow-up compared to preoperative data independent of the used method. The method for analysis of HRQoL should however be standardized in future research to make comparison between studies possible. The Bariatric Analysis and Reporting Outcome System (BAROS) might be a good instrument because it is specifically designed to analyze HRQoL in bariatric patients and has been updated recently [34, 35].

Nowadays, operative techniques in bariatric surgery are many. The performed type of surgery seems to be of little importance on HRQoL results except for the fact that RYGB usually leads to a better weight loss and therefore better quality of life $[8,18,28,36]$. On the other hand, a long-term follow-up study by Miller et al., comparing open VBG to LAGB, showed significantly better results (using the BAROS score) after a minimum follow-up of 10 years in favor of the LAGB group. The explanation for this might be the higher failure rate $(12.3 \%$ versus $3.2 \%)$ and reoperation rate $(40 \%$ versus $8 \%)$ after VBG [37]. A limitation of the latter and present study is the comparison of an open (VBG) with a laparoscopic (LAGB) approach. However, in the present study, this difference in operative technique does not seem to influence the HRQoL results, which is reported by others as well. One- and 5-year follow-up studies by Mathus-Vliegen et al. showed comparable HRQoL results after laparoscopic and open gastric banding $[23,24]$. In the present study, the impaired quality of life preoperatively in both the VBG and LAGB group was improved overall postoperatively with minor differences in HRQoL parameters. Therefore, literature findings as well as our results indicate that the impaired quality of life in morbidly obese patients is reversed by surgically
Fig. 1 Mean values of HRQoL parameters preoperatively, 1 and 7 years after restrictive procedures (VBG and LAGB, $n=84$ ). $E L$ energy level, $E R$ emotional reaction, $S I$ social isolation, $P A$ physical abilities (all NHP-I), $S A$ somatic autonomy, $M C$ mobility control, $P C$ psychic autonomy and communication, $S B$ social behavior, ES emotional stability, $M R$ mobility range (all SIP-68)

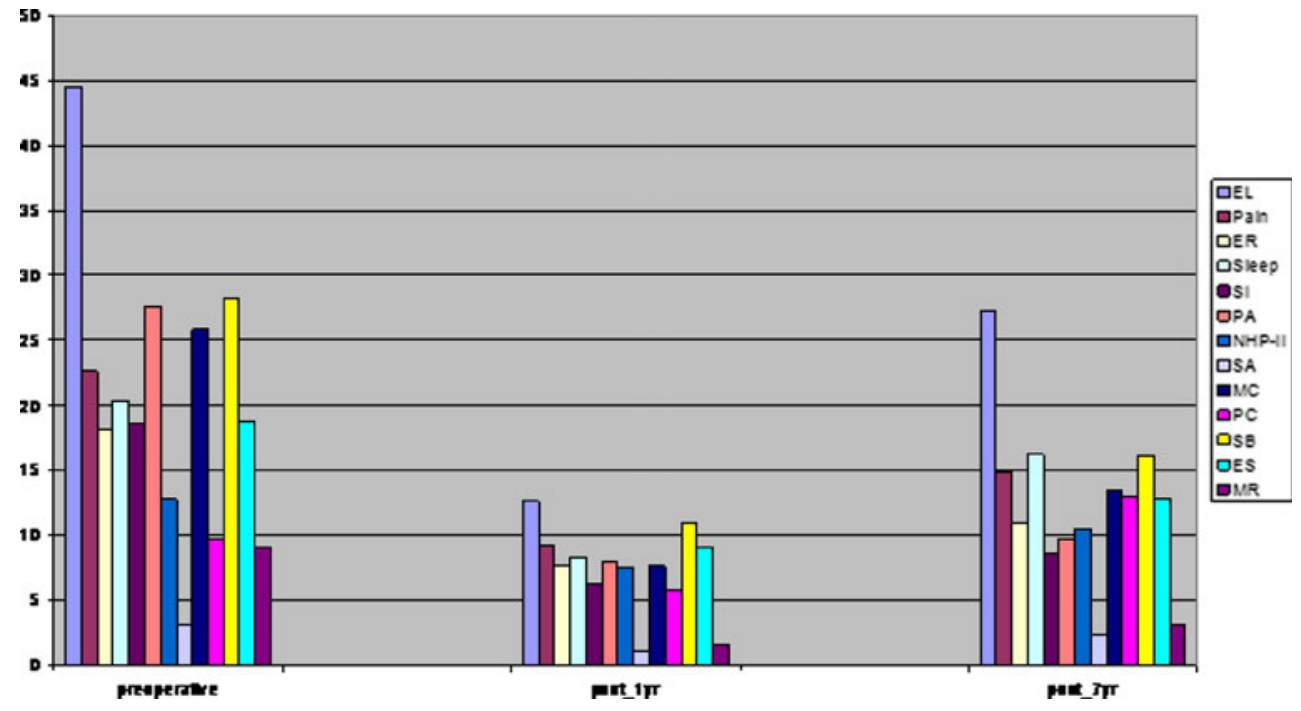


induced weight loss independent on the type and technique of the procedure.

In the present study, an important topic was if reoperations during follow-up have an influence on the HRQoL results. O'brien et al. [11] reported on 25 patients who underwent a reoperation after LAGB and described a significant improvement in seven of the eight SF-36 scales after 1 year. Dixon et al. described the results of more than 1,000 LAGB patients. One hundred and four patients underwent revisional procedures because of band erosion and prolapse. The improvement in HRQoL, using the SF36 questionnaire, was comparable in patients with or without reoperations during follow-up visits afterwards [10]. Results from the present study also suggest that reoperations during follow-up seem to be of little importance in relation to the eventual quality of life. However, a shortcoming of the present study is that HRQoL analysis was not performed just before the reoperation. It is possible that during this period the HRQoL is worse because of the failure of the primary procedure and improves after the reoperation and subsequent weight loss. Furthermore, another important shortcoming of the present study was that seven patients $(7 \%)$ were lost to follow-up and five patients $(5 \%)$ did not enter all items of the questionnaires resulting in incomplete data. It is also not known if the seven patients lost to follow-up had any reoperations.

In the study population, HRQoL parameters after 7 years are comparable between patients with or without conversion to RYGB after failure of VBG. Weight loss was also comparable between these groups. Reoperated patients in the LAGB group had even more HRQoL parameters significantly improved than patients without reoperations. Weight loss was slightly better in the reoperated group (EWL 57\% and 54\%). Therefore, these results only emphasize that long-term quality of life is mainly dependent on weight loss and decrease in comorbidities and not on the type of procedure, complications or reoperations.

\section{Conclusion}

Restrictive bariatric surgery improves quality of life. Although results are most impressive 1 year after surgery, the improvement in quality of life remains significant at long-term follow-up. Furthermore, quality of life results are mainly dependent on weight loss and reduction in comorbidities and not on the type of surgery or surgical complications.

Conflict of Interest The authors declare that they have no conflict of interest.
Open Access This article is distributed under the terms of the Creative Commons Attribution Noncommercial License which permits any noncommercial use, distribution, and reproduction in any medium, provided the original author(s) and source are credited.

\section{References}

1. Saxena S, Orley J. Quality of life assessment: the World Health Organization perspective. Eur Psychiatr. 1997;12S3:263s-6.

2. Cowan Jr GS et al. Obesity stereotypes among physicians, medical and college students. Bariatric surgery patients and families. Obes Surg. 1991;1(2):171-6.

3. Buchwald $\mathrm{H}$ et al. Bariatric surgery: a systematic review and meta-analysis. JAMA. 2004;292(14):1724-37.

4. Kral JG, Sjostrom LV, Sullivan MB. Assessment of quality of life before and after surgery for severe obesity. Am J Clin Nutr. 1992;55(2 Suppl):611S-14.

5. Abiles V et al. Psychological characteristics of morbidly obese candidates for bariatric surgery. Obes Surg. 2008;20(2):161-7.

6. van Gemert WG et al. Psychological functioning of morbidly obese patients after surgical treatment. Int $\mathrm{J}$ Obes Relat Metab Disord. 1998;22(5):393-8.

7. Steffen R et al. Successful multi-intervention treatment of severe obesity: a 7 -year prospective study with $96 \%$ follow-up. Obes Surg. 2009;19(1):3-12.

8. van Gemert WG et al. Quality of life assessment of morbidly obese patients: effect of weight-reducing surgery. Am J Clin Nutr. 1998;67(2):197-201.

9. Folope $\mathrm{V}$ et al. Weight loss and quality of life after bariatric surgery: a study of 200 patients after vertical gastroplasty or adjustable gastric banding. Eur J Clin Nutr. 2008;62(8):102230.

10. Dixon JB, Dixon ME, O’Brien PE. Quality of life after lap-band placement: influence of time, weight loss, and comorbidities. Obes Res. 2001;9(11):713-21.

11. O'Brien P, Brown W, Dixon J. Revisional surgery for morbid obesity-conversion to the Lap-Band system. Obes Surg. 2000;10 (6):557-63.

12. van Dielen FM et al. Laparoscopic adjustable gastric banding versus open vertical banded gastroplasty: a prospective randomized trial. Obes Surg. 2005;15(9):1292-8.

13. Hunt SM, McEwen J, McKenna SP. Measuring health status: a new tool for clinicians and epidemiologists. J R Coll Gen Pract. 1985;35(273): 185-8.

14. de Bruin AF et al. The sickness impact profile: SIP68, a short generic version. First evaluation of the reliability and reproducibility. J Clin Epidemiol. 1994;47(8):863-71.

15. de Bruin AF et al. The development of a short generic version of the Sickness Impact Profile. J Clin Epidemiol. 1994;47(4):407-18.

16. de Bruin AF et al. Assessing the responsiveness of a functional status measure: the Sickness Impact Profile versus the SIP68. J Clin Epidemiol. 1997;50(5):529-40.

17. Sullivan M et al. Swedish obese subjects (SOS) - an intervention study of obesity. Baseline evaluation of health and psychosocial functioning in the first 1743 subjects examined. Int J Obes Relat Metab Disord. 1993;17(9):503-12.

18. Hell $\mathrm{E}$ et al. Evaluation of health status and quality of life after bariatric surgery: comparison of standard Roux-en-Y gastric bypass, vertical banded gastroplasty and laparoscopic adjustable silicone gastric banding. Obes Surg. 2000;10(3):214-19.

19. Kinzl JF et al. Quality of life in morbidly obese patients after surgical weight loss. Obes Surg. 2007;17(2):229-35.

20. Mathus-Vliegen EM. Long-term health and psychosocial outcomes from surgically induced weight loss: results obtained in 
patients not attending protocolled follow-up visits. Int $\mathrm{J}$ Obes (Lond). 2007;31(2):299-307.

21. Champault A et al. Quality of life after laparoscopic gastric banding: prospective study (152 cases) with a follow-up of 2 years. Surg Laparosc Endosc Percutan Tech. 2006;16(3):131-6.

22. Dziurowicz-Kozlowska A et al. Health-related quality of life after the surgical treatment of obesity. J Physiol Pharmacol. 2005;56 Suppl 6:127-34.

23. Mathus-Vliegen EM, de Wit LT. Health-related quality of life after gastric banding. Br J Surg. 2007;94(4):457-65.

24. Mathus-Vliegen EM, de Weerd S, de Wit LT. Health-related quality-of-life in patients with morbid obesity after gastric banding for surgically induced weight loss. Surgery. 2004;135(5):489-97.

25. Nguyen NT et al. Laparoscopic versus open gastric bypass: a randomized study of outcomes, quality of life, and costs. Ann Surg. 2001;234(3):279-89. discussion 289-91.

26. Karlsson $\mathrm{J}$ et al. Ten-year trends in health-related quality of life after surgical and conventional treatment for severe obesity: the SOS intervention study. Int J Obes (Lond). 2007;31(8):1248-61.

27. Waaddegaard P, Clemmesen T, Jess P. Vertical gastric banding for morbid obesity: a long-term follow-up study. Eur J Surg. 2002;168(4):220-2.

28. Muller MK et al. Quality of life after bariatric surgery-a comparative study of laparoscopic banding vs. bypass. Obes Surg. 2008;18 (12):1551-7.
29. van Hout GC et al. Health-related quality of life following vertical banded gastroplasty. Surg Endosc. 2009;23(3):550-6.

30. de Zwaan $\mathrm{M}$ et al. Health-related quality of life in morbidly obese patients: effect of gastric bypass surgery. Obes Surg. 2002;12 (6):773-80

31. Sanchez-Santos R et al. Long-term health-related quality of life following gastric bypass: influence of depression. Obes Surg. 2006;16(5):580-5.

32. Larsen JK et al. Psychosocial functioning before and after laparoscopic adjustable gastric banding: a cross-sectional study. Obes Surg. 2003;13(4):629-36.

33. Waters GS et al. Long-term studies of mental health after the Greenville gastric bypass operation for morbid obesity. Am J Surg. 1991;161(1):154-7. discussion 157-8.

34. Oria HE, Moorehead MK. Bariatric analysis and reporting outcome system (BAROS). Obes Surg. 1998;8(5):487-99.

35. Oria HE, Moorehead MK. Updated bariatric analysis and reporting outcome system (BAROS). Surg Obes Relat Dis. 2009;5(1):60-6.

36. van Gemert WG et al. Revisional surgery after failed vertical banded gastroplasty: restoration of vertical banded gastroplasty or conversion to gastric bypass. Obes Surg. 1998;8(1):21-8.

37. Miller K, Pump A, Hell E. Vertical banded gastroplasty versus adjustable gastric banding: prospective long-term follow-up study. Surg Obes Relat Dis. 2007;3(1):84-90. 